Article

\title{
Sport for Vulnerable Youth: The Role of Multi-Professional Groups in Sustaining Intersectoral Collaboration
}

\author{
Chiara D’Angelo *, Chiara Corvino, Eloisa Cianci and Caterina Gozzoli \\ Department of Psychology, Catholic University of Milan, 20123 Milan, Italy; E-Mails: chiara.dangelo@unicatt.it (C.D.), \\ chiara.corvino1@unicatt.it (C.C.), eloisa.cianci@unicatt.it (E.C.), caterina.gozzoli@unicatt.it (C.G.) \\ * Corresponding author
}

Submitted: 30 December 2019 | Accepted: 23 April 2020 | Published: 17 August 2020

\begin{abstract}
Intersectoral actions in the sport-for-development field constitute a pre-condition for the implementation of sport-based interventions. At an operational level, the multi-professional group is the tool through which intersectoral collaboration may successfully achieve its aims. Despite the prominent role of the group, this topic is under-researched in terms of understanding intersectoral actions in the sport-for-development field. By applying a psycho-sociological perspective, our research explores the role of the multi-professional group as a limit/resource for sport-for-development workers that operate with vulnerable youth. Following a phenomenological interpretive approach, 12 practitioners (six sport workers and six social workers) participated in semi-structured interviews to explore the role of multi-professional groups as a resource/limit in working with socially vulnerable youth through sport. The results indicate that, in the participants' experience, belonging to a multi-professional group is a meaningful resource to trigger reflexivity, promote collaboration and integrate their different professions. The interviews highlighted the positive potential of this tool to address the challenges that emerge when working with socially vulnerable youth, including the management of negative emotions, unexpected events and the relationship with young people. Some interviews also suggested that the presence of multiple professions, under certain circumstances, may be a risk when working with youth. These findings have significant value for programme design, strategy and management as they show the value of trans-disciplinary practices as an agenda for social inclusion through sport.
\end{abstract}

\section{Keywords}

intersectoral collaboration; multi-professional group; social vulnerability; sports; youth

\section{Issue}

This article is part of the issue "Sport for Development: Opening Transdisciplinary and Intersectoral Perspectives" edited by Pascal Delheye (Ghent University, Belgium), Kirsten Verkooijen (Wageningen University \& Research, The Netherlands), Dan Parnell (University of Liverpool, UK), John Hayton (Northumbria University, UK) and Reinhard Haudenhuyse (Vrije Universiteit Brussel, Belgium).

(C) 2020 by the authors; licensee Cogitatio (Lisbon, Portugal). This article is licensed under a Creative Commons Attribution 4.0 International License (CC BY).

\section{Introduction}

Sport for Development (SFD) programmes for vulnerable youth have significantly increased in the last decade (Corazza \& Dyer, 2017; Dukic, McDonald, \& Spaaij, 2017; Nols, Haudenhuyse, \& Theeboom, 2017). Such interventions generally aim either to develop inclusion in sport or inclusion through sport (Coalter, 2002). In the first paradigm, programmes facilitate access to sport participation by tackling infrastructural or economic barriers that limit engagement in sport (Vandermeerschen, Vos, \& Scheerder, 2015). In the second paradigm, sport is used to address the needs of vulnerable populations (Gozzoli, D’Angelo, \& Confalonieri, 2013; Levermore \& Beacom, 2009; Schulenkorf, 2012). In this second approach, sport, if properly used, may constitute an oppor- 
tunity to sustain several benefits among socially vulnerable youth, including participation, education, social inclusion, life skills, work skills and health (D’Angelo, Corvino, De Leo, \& Sanchéz, 2019; Hermens, Super, Verkooijen, \& Koelen, 2017; Holt et al., 2017). However, sport can also trigger negative effects such as social exclusion, doping, match fixing (Coalter, 2017).

Several authors have reported that research on sport should outline under which conditions and through which mechanisms sport can be an effective in encouraging positive social development (Coalter, 2017; Schaillée, Haudenhuyse, \& Bradt, 2019; Whitley et al., 2019).

At present, intersectoral actions in the sport-fordevelopment field constitute a meaningful condition for the implementation of sport-for-development interventions (Lindsey \& Bitugu, 2019; Misener \& Doherty, 2012). Intersectoral collaboration cannot be fully understood without considering the role of the multi-professional work group. A work group is a system of two or more individuals who are interconnected (face-to-face or virtually) and interdependent in sharing a common goal of working and performing organisational tasks (Arrow, McGrath, \& Berdahl, 2000; Kozlowski \& Bell, 2003). The work group is prominently important at an organisational level, because it is a tool through which an organisation may successfully achieve its aims by defining clear tasks and roles (Kozlowski \& Bell, 2003). In this domain, the sharing of skills and expertise that underpins intersectoral actions requires the constitution of a new work group composed of diverse professionals who meet and capitalise on their knowledge for a common purpose. Thus, when understanding intersectoral actions, the functioning of such multi-professional groups at the managerial or operational level is particularly important in determining whether or not such collaboration is successful.

However, research in this field has mainly analysed intersectoral collaboration through factors that inhibit or support a partnership from a macro perspective (Lindsey \& Bitugu, 2019). These include personal elements (e.g., personal commitments in the partnership and relationships), institutional elements (e.g., organisational commitment and societal and political context) and organisational elements (e.g., leadership, task management, communication structure, building on capacities, visibility; Hermens, Verkooijen, \& Koelen, 2019; Koelen, Vaandrager, \& Wagemakers, 2012). An understanding of the role of multi-professional groups is still lacking. This topic is also under-researched within the Italian context of sport and development (Svensson \& Woods, 2017) and in relation to youth's social vulnerability (Jones, Edwards, Bocarro, Bunds, \& Smith, 2017). By analysing the representation and feelings of the workers, the aim of our study is to explore the role of the multi-professional group as a limit/resource for sport-fordevelopment workers that operate with socially vulnerable youth. The study seeks to answer the following question: is the multi-professional group a resource or limit for workers of sport-based intervention and how so?

\section{Intersectorial Actions in Sport-Based Intervention for Socially Vulnerable Youth}

In defining vulnerable youth, the fluidity and uncertainty of social and personal identities need to be considered, as do the transformations in family roles in contemporary society, as these expose every child or youth to some kind of 'vulnerability' (Bauman, 2005). It is especially critical to differentiate people who are vulnerable from people who are not, although the risk of stigmatisation that this type of categorisation fosters has been widely criticised (Sperling, 2020). Although we are aware of these challenges, in this study we understand socially vulnerable youth as a specific group of young people who are daily subjected to multifaceted stressors (e.g., social, emotional and economic), which include poor family management, poverty, deviant conduct, lack of motivation, disaffection towards institutions and lack of social networks, which may lead to social maladjustment (Galuppo, Gorli, Alexander, \& Scaratti, 2019; Haudenhuyse, Theeboom, \& Skille, 2014; Regoliosi \& Scaratti, 2010). Tackling these fragilities is delicate and complex and, thus, requires specific attention involving a diverse set of skills from different professional fields (Edwards, Lunt, \& Stamou, 2010). Various studies have investigated the success of collective actions promoted by different professionals, particularly when delivering programmes or services to vulnerable populations (Camiré, Trudel, \& Forneris, 2012; Holt et al., 2017; Yohalem, Wilson-Ahlstrom, Fischer, \& Shinn, 2009).

The literature from the sport and development field agrees that such interconnections between sectors and professionals are crucial in the successful inclusion of vulnerable youth in institutionalised sport settings and the broader community. For instance, Jones et al. (2017) noted that youth sport programmes should stipulate collaboration with community organisations by sharing expertise and resources through an integrated curriculum. Spaaij (2012) has highlighted that youth development is prominently associated with a programme's capacity to promote connections with multiple institutional agents. Nevertheless, in a recent review, Holt et al. (2017) reported the meaningful role of distal ecological systems (e.g., the community) in developing outcomes and changes for individual youths through sport. Because the sport sector is generally better equipped to develop technical sport skills while social entities have a deeper expertise concerning pedagogical, psychological and educational skills (Coalter, 2013; Sanchéz, Gozzoli, \& D'Angelo, 2013), the integration of these entities could ensure that vulnerable youth receive the comprehensive care they need (Hermen, Super, Verkooijen, \& Koelen, 2015; Marlier et al., 2015).

\section{Intersectoral Actions: The Role of the Group}

Intersectoral actions are formal collaborations or partnerships among organisations or people with different 
backgrounds and expertise that work together to achieve a common goal. In this domain, intersectoral actions require the definition of a common work purpose and the presence of different sectors, such as the sport and social sector, to tackle that purpose (Corbin, Jones, \& Barry, 2016). The achievement of the organisational goal, including that of an intersectoral collaboration, requires the presence of a work group (Kozlowski \& Bell, 2003). A work group is an interdependent and interconnected social system in which individuals cooperate to achieve organisational tasks (Arrow et al., 2000; Kozlowski \& Bell, 2003). The group constitutes the meso-level between the individual and the wider organization, included those that are interconnected through a partnership, which makes it possible to address a common scope (Kozlowski \& Bell, 2003). The peculiarity of the work group that cooperates in an intersectoral action is the presence of multiple professionals belonging to different sectors and disciplines (Lindsey \& Bitugu, 2019).

In this study, we explore the role of multiprofessional groups in intersectoral actions using a psychosociological perspective (Barus-Michel, Enriquez, \& Lévy, 2005). This framework was developed as an interpretative perspective for organisational contexts. Starting from the intersection of contributions from sociology, social psychology and psychoanalysis, the psychosociological approach provides an interpretative key for organisational phenomena. This approach analyses the interconnections between the individual, the group and the organisation, as well as how these influence each other (Barus-Michel et al., 2005). The peculiarity of this approach is that the work group is considered both as a resource and a limit to organisational success. The work group may constitute an important resource in understanding one's own emotions, allowing the worker to reflect and co-build shared meanings for the work experience. The cooperation and relationships with the other can, however, lead to dysfunctional and risky dynamics such as mobbing or destructive conflicts, which may have negative consequences in terms of achieving the organisational purpose (Cabiati, Ripamonti, \& Pozzi, 2016; Scaratti, Gorli, \& Ripamonti, 2009).

\section{Methods}

By analysing the representation and feelings of the workers, our study seeks to answer the following question: Is the multi-professional group a resource or limit for workers of sport-based intervention for vulnerable youth and how so?

Following a phenomenological interpretive approach (Smith \& Osborn, 2008), we involved 12 practitioners (six sport workers, including five sport coaches and one sport administrator; six social workers, including three educators and three psychologists) in semistructured interviews. The sample was selected using convenience sampling. We selected the sample by including sport and social workers from Italian sport- based programmes for vulnerable youth who were in our network from previous evaluation research projects (Gozzoli et al., 2013). We used this sampling approach because these workers were involved in sport programmes that had meaningfully features for the aim of this research: 1) These programmes are plus-sport interventions in which sport is used as a social context for socially vulnerable youth work (Coalter, 2007); 2) they are implemented through the collaboration of both social and sport organisations (i.e., intersectoral action was present); and 3) both social workers and sport workers were present during sport sessions with the youth (i.e., there is a new multi-professional group composed of different professionals who collaborate on the ground with youth).

We used the semi-structured interview format to explore the phenomena of multi-professional group as a resource or limit to work with socially vulnerable youth through sport. Because Interpretative Phenomenological Approach is used to study the meanings experience hold for participants (Smith \& Osborn, 2008), the interview schedule included questions about representations and feelings about the role of the multi-professional group as a resource or limit for sport-based workers (e.g., 'How does the multi-professional group help you in your work with youth?' and 'How does the multi-professional group limit your work with youth? How does the multi-professional group help to achieve project goals?').

Interviews were collected within the last three years and lasted around 40-45 minutes. The interviews were conducted in Italian, recorded, transcribed by hand, anonymised and analysed using paper-pencil content analysis method by applying an inductive and deductive process of categorisation (Hsieh \& Shannon, 2005). During the first phase of the analysis, we used deductive content analysis to point out macro-categories related to group resources and limits expressed in the interviews. We highlighted widely where the interviewees talked about the group as a limit or as a resource. Subsequently, we applied inductive content analysis to create sub-categories related to group resources and limits. In this domain, we detailed participants' representations and feelings of the two macro-categories. The bottom-up logic of categorisation was used because it is not possible to determine in advance which microcategory will sustain each category related to group resources and limits. The entire analysis process was conducted by two independent researchers (Chiara Corvino and Chiara D'Angelo); the researchers analysed cases of divergence until an agreement was reached.

The authors declare that the procedure met the international norms and ethical principles established by the European Union 2016/679 Regulation, the Declaration of Helsinki established by the World Medical Association (1964) and related revisions with written informed consent obtained from each participant. 


\section{Results}

The results show that, in interviewees' experience, belonging to a multi-professional group is a meaningful resource to trigger reflexivity, promote collaboration and integrate the different professions. We need to specify there that participants often used the word 'interprofessional supervision' to talk about the group; this term is used in the Italian psycho-educational and medical fields to indicate a team of professionals from different disciplines (generally educators, psychologists, psychiatrists or doctors) who gather to discuss the cases they are treating. The interviews (see Table 1) highlight the positive potential of multi-professional groups to address some of the challenges that emerge when working with socially vulnerable youth through sport, including the management of negative emotions, unexpected events and the relationship with young people. Although the data yield a positive representation of the group as a resource for intersectoral collaboration, some interviews suggested that the presence of multiple professions risks creating confusion or overlaps when working with youth.

\subsection{Resources}

\subsubsection{Group as a Resource to Manage Negative Emotions}

Sport and social workers reported the struggle of managing youth deviant conduct. In the interviewees' experiences, youth had different difficulties during sport sessions: They had physical conflicts with their peers, they insulted adults or peers or they were twitchy and nervous. All of these behaviours had an impact on workers, who claimed to feel tired and stressed after programme activities. The interviewees pointed out that one of the most difficult parts of their work was coping with the emotional fatigue related to vulnerable youth conduct:

In my opinion, the emotions of workers are important to consider. The first trainings with youth were very challenging: Participants didn't respect rules, they were not able to keep their concentration and we too had some difficulties in limiting them. (Social worker)

This issue was particularly challenging for sport coaches, who were not used to such situations in the sport context. The words of one sport coach summed up this challenge:
At the beginning of the project we had some difficulties...the training was fine, but immediately after something happened that let you down [the coach is talking about episodes of brawling after the programme activities]. Emotionally, it is something that really affects you in this type of project. In my work inside the sport club it had never happened to me. I mean, when I'm in the field I am the coach, but here....I do not say that I am something more, but I care about the success of their path, don't I? So, when something out of the blue happens, something deviant, you feel disappointment and discomfort.

A separation between the work of coaches in a conventional sport environment - the grassroots sport societyand in the sport-based programmes emerged. In the interviews, participants reported that the role of coaches changed: The emotional involvement of coaches was higher compared than that of the social workers, as was their distress if youth disappointed the adults' expectations. This can be seen in the words of another sport coach:

The coach here has a different role: You need to be a friend, you need to be a coach, you need to be a brother, you need to be a dad-you need to be everything they need, for each of them.

The coaches who work with socially vulnerable youth thus seem to identify totally with the vulnerabilities of the youth (i.e., the lack or absence of adequate parental figures; lack of positive social relationships) and feel responsible for filling the resulting emotional and social void. The coach is a friend, a brother-in some cases even a father. However, this thought cannot be fully realised: At some point, the coach will face the limit of his own role and consequently become frustrated. The results highlight the differences in how coaches and social workers manage emotions in working with at-risk youth: Coaches seem less prepared, and therefore more vulnerable, in tolerating the failures, frustrations and limits of their actions. This separation leads them to focus more on psychological issues, which is the part of the work with vulnerable youth for which they feel less prepared: "In this programme, I didn't really work on technical, tactical, athletic aspects. I focused more on the psychological side of the activity" (Sport coach).

In this domain, it emerged that the presence of a multi-professional group helped coaches to better cope

Table 1. Macro and micro categories of the research.

\begin{tabular}{ll}
\hline Macro-category & Micro-category \\
\hline Resource & Group as a resource to manage negative emotions \\
& Group as resource to manage unpredictable situations \\
Risk & Group as a resource to manage the relationship with youth \\
\hline
\end{tabular}


with this challenge, as they received reflective feedback from the social workers. In the inter-professional supervision, social workers shared their competence and supported coaches in understanding their reactions towards the youth. The multi-professional group became a space where workers could reflect and share interpretations about their own behaviour with youth. In particular, for sport workers, the group was useful in engaging with the competence of social workers and helped the sport workers to modulate their emotional reactions, especially when the youth showed deviant conduct. One coach summarises this aspect:

In my sport society, I am the coach, I make the decision and that's it: There is no one who tells me 'no you did it wrong, yes you did it well.' Here, there was also the moment after I made a decision, when I faced an educator. In most cases he told me 'yes, you did it well or you can change, try to fix the situation this way.' It was helpful to have feedback after my actions. During one interprofessional supervision, we discussed the behaviour of some participants [the interviewee is talking about poor behaviour]. After the interprofessional supervision, I acted and took into consideration what we had shared during the discussion. Thus, working as a group with people who have skills that differ from mine was certainly useful for the educational purposes of the project. (Sport coach)

\subsubsection{Group as Resource to Manage Unpredictable} Situations

As a consequence of youth conduct, the data showed another important related challenge: Sport programme personnel did not have complete control of training planning and implementation. Actually, the mood of the youth could potentially change what they had previously planned:

Here something strange happened, something a little more complicated than normal. Thus, having the firmness and the...coldness, also, to make a decision in a very short space of time can surely help a person who works in similar projects. You have to be prepared for everything, because when I really saw guys who were about to hit, I had to raise my voice! You need to be ready for everything! (Sport coach)

The interviewees reported that the presence of a multi-professional group on the ground may be useful in reading and interpreting the dynamics between youth when something unpredictable and fast happens. Because the sport coach is focused on the training itself, the multiple 'eyes' on the participants helps in understanding why they have behaved in a certain way when sharing reflections during the interprofessional supervision:
When the team is large it can be helpful to have 'two eyes' on the field: It is not bad. From the outside we can see things that we cannot see from the inside. (Sport coach)

During the interprofessional supervision, we realised that we saw different things during the trainings [the interviewee here refers to her-or himself as a social worker and to the sport coach]. There are 15 boys, sometimes 16 , sometimes 17 boys, and they are scattered in the gym. It is clear that if the sport coach is turned to one side and I'm turned to the other, we see two different things. Or even if we are looking at the same situation, we read it in two different ways, and therefore it is important to talk to each other. (Social worker)

\subsubsection{Group as a Resource to Manage the Relationship with Vulnerable Youth}

Programme workers widely describe the challenge of maintaining a relationship of appropriate closeness with the youth. On the one hand, the relationship requires support and closeness, while on the other hand, the youth also need to recognise the authority of the adults and rules. To make the relationship with youth effective, these two relational elements should be held together, as these sport coaches explain:

The relationship you need to have with them-you need to be one of them, but at the same time they need to understand that you are the one there, that you are the coach, but that you speak and move in their ways, then you can do it. (Sport coach)

You are the coach, yes, true, but you need to be a little...distant, somehow-but not too much. I mean, the youth need to feel you are close to them to take you as an example. (Sport coach)

These poles of the relationships are not described by the participants in a fragmented way rather the need to create $a$ balance between them is clear. The first component is described as particularly challenging to convey in the work with youth, because participants often disregard the rules of coexistence. It is therefore important for operators to provide a clear value structure to which the youth can refer and in which they can find security. This component, although it is difficult to implement, is essential to keep the youth together and to promote their inclusion, because it is precisely through the rules that it is possible for each to enter into a positive relationship with the other:

Even if it is difficult, it is important to give them precise rules.... when I talk about rules, I mean the rules that we put in-listening and respect, which are clearly very general rules - but I think that those simple rules 
are useful to stay together in the sport field for that hour and a half. And they will be useful once they're out in their daily life. (Social worker)

In this domain, the interviews highlighted that the multiprofessional group is a useful device to find out how to manage the relationship with youth by analysing their needs and setting common relationship rules:

Working in a group with the coach, the psychologist, and I...working side by side-jointly-was very positive for me. We set some basic rules to use with the boys. This allowed us to give the youth the same feedback and to manage emergency situations in a common way. (Social worker)

During the interprofessional supervision we talked a lot about the youth and the 'measures' to use with them in the sport setting...especially for the ones who are more troubled, we tried to understand them and how to relate with them. (Sport coach)

This was particularly useful for coaches, who acquired new skills and learned new ways to relate with the youth:

During the interprofessional supervision, we saw how coaches slowly acquired new knowledge. I saw that some coaches started using educative language. They developed a different perspective on the youth, they tried to make interpretations about youth behaviours saying, 'maybe this thing in this situation meant....' Also during trainings, they took the responsibility of doing something more educational. (Social worker)

The co-presence of social workers enhanced the professional integration of sport coaches and seemed to be useful to improve the coaches' relational work with the youth. In this domain, there seemed to be a disparity between professionals. The coaches needed to acquire support and skills from the social workers to carry on their work with the vulnerable youth, rather than the opposite.

\subsection{Risks: Group as a Risk that Create Double-Leadership}

Although the multi-professional group is meaningfully useful for all of the reasons mentioned, the social workers pointed out that the co-managing of training with coaches is not simple. There is the risk of creating a double-leadership which may be confusing for the young people, who need clear and defined role models:

Well, it is not easy...I try not to enter [the interviewee is talking about the fact that he/she tries not to intervene during the training in place of the sport coach] even if sometimes I would like to enter in the game and play with the boys. I understood that en- tering in the game might not be positive for the role of the coach toward the boys....It could interfere, because during the activity the youth should refer to him....Probably, if you enter in the game, you create a double role. (Social worker)

\section{Discussion of Results and Conclusion}

The intersection of diverse skills and competences in a work group makes it possible to overcome some of the challenges of working with socially vulnerable youth in sport-based interventions. The first of these challenges is that the vulnerabilities of youth have an emotional impact even on the workers taking care of them, especially for the sport coaches (Gozzoli, Gazzaroli, \& D'Angelo, 2018). In line with psychosociological assumptions, the multi-professional group can serve as a tool to focus on these difficulties and elaborate them. When the group operates in this way, it becomes an emotional container where people can build meaning based on emotions through sharing their thoughts with others (Bion, 1962). This exchange has indeed allowed coaches to receive feedback on their actions, and this has enhanced their reflexivity. As pointed out by Galuppo, Gorli, Scaratti, and Kaneklin (2014), exchange with others inside a work group may trigger self-awareness and introspection, and this positively affects on how people manage their emotions at work.

The second challenge involves the management of unpredictable situations, and the sharing of different perspectives on youth was helpful for the workers to interpret why and how certain situations occurred during trainings. This is in line with the psychosociological perspective, which highlights the unpredictable and creative outcomes generated by the interdependency of diverse individuals inside the group (Lewin, 1951).

The final challenge concerns the creation of a good balance between relational closeness and establishing a good authority relationship with the youth. As pointed out by Coalter (2013) and Haudenhuyse, Theeboom, and Coalter (2012), the quality of the relationship established between youth and the programme workers is a key mechanism in such sport for the development initiatives. This relationship is one of the main working nodes to support young people in their educational paths and can be considered a sort of pre-condition for working with vulnerable youth through sport. The challenge involving SFD personnel concerns the fact that both poles of the quality of the relationship, ethical and affective (Alfieri, et al., 2018; Cigoli \& Scabini, 2007), should be supported. The presence of professionals with non-sport skills was a source of support for coaches, who improved their capacity to relate towards youth. However, the copresence of several professionals during training may obstruct the relationship with youth by creating fragmented role models.

Although this research mainly highlights the positive aspects of working in a multi-professional group, 
the psychosociological approach warns us against certain risks. First, the multi-professional group is not always a place for emotional reworking and constructive exchange with the other. The relationship with the other can also lead amplify negative emotions and create conflicts which, if not properly managed, become destructive and impair the achievement of the organisational objective. The formation of the work group is not immediate, however, and requires appropriate coordination leading to the construction of a clear and shared work object with which people can identify and build a sense of belonging (Gazzaroli, Gozzoli, \& Gardey, 2019; Gozzoli, 2016a, 2016b). Despite the positive role of the work group in intersectoral collaboration, the psychological effort of dealing with individuals belonging to organisations with diverse cultures, practices and organisational values should be taken into account.

In terms of the wider sport for development literature, these results confirm the meaningful role of intersectoral collaboration and draw attention to the copresence of different skills and knowledge, which serve as an added value for sport-based interventions (Lindsey \& Bitugu, 2019).

In more detail, the multi-professional group helped in achieving the purpose of the intersectoral collaboration from two points of view: 1) The exchange with other professionals in the group mitigated sport coaches' vulnerability and helped them in finding out strategies to improve their daily work with youth. Thus, the group enhanced reflection and led to increased awareness and introspection by coaches about their work with youth (Galuppo et al., 2014; Stelter, 2009, 2014). Nevertheless, the group enhanced sport workers' educative learnings about vulnerable youth. In this regard, the presence of professionals with non-sport skills was a source of support for coaches who comprehensively improved their behaviours towards youth; and 2) the group facilitated educative synergies and coherence between social and sport workers and avoided dissonance between them.

There are several implications of this work for future sport-based interventions and policymakers. First, to generate effective collaboration between sectors in the micro sport environment with youth, this study highlights that SFD personnel need space and time for face-to-face contact and interpersonal cooperation. This means that engaging SFD personnel in common group practices can support them in their work with vulnerable youth. This result also emerged in previous studies on SFD intersectoral action, in which sport workers and social workers pointed out the lack of time to build and maintain the personal relationships necessary for intersectoral action and inclusive sport activities (Hermens et al., 2015). Sharing space and time together can also be helpful in developing a trans-disciplinary methodology and inter-professional culture for working with vulnerable youth through sport (Edwards et al., 2010). The interviewees talked about the usefulness of the inter- professional supervision as a formal device in which different professionals physically meet, exchange opinions and reflect on the actions carried out with the youth (Scaratti et al., 2009). This kind of practice should be encouraged when planning sport-based interventions, because it is in the inter-professional meetings that SFD staff could experience and take advantage of the value of intersectoral collaborations.

Second, a proper monitoring and coordination of such groups should be introduced. The role of project managers or professionals coordinating the multi-professional group is crucial to enhance interprofessional integration. This is particularly important since, according to the coaches themselves, the professional knowledge of the SFD coaches (Côté \& Gilbert, 2009) is less relevant when working with vulnerable youth. The research highlights that a transprofessional culture and methodology integrating psycho-pedagogical dimensions with the sport dimensions is still in its infancy in Italy. In the context of this study, this can be explained culturally by the Italian sport system, in which there is a strong opposition between the 'sport for all' ideology and competitive sport, which is more focused on the development of technical sport skills. An integration of the two philosophies should be considered critically (Porro, 2020). The need of coordination is, thus, meaningful.

Nevertheless, the research highlights the importance to properly finance the back-office work in sport-based intervention in order to micro-plan, reflect and find out common strategies to accurately work with vulnerable youth through sport. In this domain, national and international funding should not only focus on the practice of sport but should also consider inter-professional supervision as a useful back-office practice to be financially supported.

\section{Limitations}

This study examined a limited sample of Italian practitioners in which the work in interprofessional supervision had a fundamental role and was supported by appropriate financial resources in programme implementation. Not all sport-for-development programmes have this unique feature, and it is not always sustainable to create face-to-face engagement between social workers and sport workers.

Future studies should cross-analyse diverse programs at both Italian and international level in order to understand widely the role of multi-professional groups. Longitudinal studies should be further considered in order to understand how the work group evolve during time and how it impacts on the efficacy of the intervention itself. Although the study has limited generalizability, the research provides some insight into the value of such multi-professional groups, which can be taken into account when planning sport-based interventions. 


\section{Acknowledgments}

We thank you all the sport and social workers involved in the interviews.

\section{Conflict of Interests}

The authors declare no conflict of interests.

\section{References}

Alfieri, S., Tagliabue, S., Marta, E., Aresi, G., Lanz, M., \& Pozzi, M. (2018). Gratitude as a variable of mediation between parental support and self-esteem in adolescence. Journal of Child and Family Studies, 27(5), 1394-1401.

Arrow, H., McGrath, J. E., \& Berdahl, J. L. (2000). Small groups as complex systems: Formation, coordination, development, and adaptation. London: Sage.

Barus-Michel, J., Enriquez, E., \& Lévy, A. (Eds.). (2005). Dizionario di psicosociologia [Psychology dictionary]. Milan: Cortina.

Bauman, Z. (2005). Liquid life. Cambridge: Polity Press.

Bion, W. R. (1962). Learning from experience. Oxford: Routledge.

Cabiati, M., Ripamonti, S., \& Pozzi, M. (2016). Creating knowledge and enhancing change in organisations: The contribution of authorship and expansive learning in a case study. Learning, Culture and Social Interaction, 11, 97-104. http://dx.doi.org/10.1016/j.lcsi. 2016.06.001

Camiré, M., Trudel, P., \& Forneris, T. (2012). Examining how model youth sport coaches learn to facilitate positive youth development. Physical Education and Sport Pedagogy, 19(1), 1-17.

Cigoli, V., \& Scabini, E. (2007). Family identity: Ties, symbols, and transitions. New York, NY: Psychology Press.

Coalter, F. (2002). Sport and community development: $A$ manual. Edinburgh: Sportscotland.

Coalter, F. (2007). Sports clubs, social capital and social regeneration: Ill-defined interventions with hard to follow outcomes? Sport in Society, 10(4), 537-559.

Coalter, F. (2013). 'There is loads of relationships here': Developing a programme theory for sport-for-change programmes. International Review for the Sociology of Sport, 48(5), 594-612. https://doi.org/10.1177/ 1012690212446143

Coalter, F. (2017). Sport and social inclusion: Evidencebased policy and practice. Social Inclusion, 5(2), 141-149. http://dx.doi.org/10.17645/si.v5i2.852

Corazza, M., \& Dyer, J. (2017). A new model for inclusive sports? An evaluation of participants' experiences of mixed ability rugby. Social Inclusion, 5(2), 130-140. http://dx.doi.org/10.17645/si.v5i2.908

Corbin, J. H., Jones, J., \& Barry, M. M. (2016). What makes intersectoral partnerships for health promotion work? A review of the international literature.
Health Promotion International, 33(1), 4-26. https:// doi.org/10.1093/heapro/daw061

Côté, J., \& Gilbert, W. (2009). An integrative definition of coaching effectiveness and expertise. International Journal of Sports Science \& Coaching, 4(3), 307-323. https://doi.org/10.1260/174795409789623892

D’Angelo, C., Corvino, C., De Leo, A., \& Sanchéz, R. M. (2019). How can performing arts and urban sport enhance social inclusion and interculturalism in the public space? Comunicazioni Sociali, 1, 142-155. http://dx.doi.org/001200_000050

Dukic, D., McDonald, B., \& Spaaij, R. (2017). Being able to play: Experiences of social inclusion and exclusion within a football team of people seeking asylum. Social Inclusion, 5(2), 101-110. http://dx.doi.org/ 10.17645/si.v5i2.892

Edwards, A., Lunt, I., \& Stamou, E. (2010). Inter-professional work and expertise: New roles at the boundaries of schools. British Educational Research Journal, 36(1), 27-45. https://doi.org/10.1080/ 01411920902834134

Galuppo, L., Gorli, M., Alexander, B., \& Scaratti, G. (2019). Leading in social entrepreneurship: Developing organizational resources in confrontation with paradoxes. Research in Organizational Change and Development, 27, 167-186.

Galuppo, L., Gorli, M., Scaratti, G., \& Kaneklin, C. (2014). Building social sustainability: Multi-stakeholder processes and conflict management. Social Responsibility Journal, 10(4), 685-701 https://doi.org/10.1108/ SRJ-10-2012-0134

Gazzaroli, D., Gozzoli, C., \& Gardey, G. S. (2019). The living and working together perspective on creativity in organizations. Frontiers in Psychology, 10. https:// doi.org/10.3389/fpsyg.2019.02733

Gozzoli, C. (2016a). Living and working together in organizations. Theme relevance: An introduction. World Futures, 72, 219-221. https://doi.org/ 10.1080/02604027.2016.1245528

Gozzoli, C. (2016b). Living and working together in organizations: Traces and ways. World Futures, 72, 222-233. https://doi.org/10.1080/02604027.2016.1245535

Gozzoli, C., D’Angelo, C., \& Confalonieri, E. (2013). Evaluating sport projects which promote social inclusion for young people: A case study. Revista Iberoamericana de Psicologia del Ejercicio y el Deporte, 8(1), 145-163.

Gozzoli, C., Gazzaroli, D., \& D'Angelo, C. (2018). Who cares for those who take care? Risks and resources of work in care homes. Frontiers in Psychology, 9. https://doi.org/10.3389/fpsyg.2018.00314

Haudenhuyse, R. P., Theeboom, M., \& Coalter, F. (2012). The potential of sports-based social interventions for vulnerable youth: Implications for sport coaches and youth workers. Journal of Youth Studies, 15(4), 437-454. https://doi.org/10.1080/13676261. 2012.663895

Haudenhuyse, R. P., Theeboom, M., \& Skille, E. A. (2014). 
Towards understanding the potential of sports-based practices for socially vulnerable youth. Sport in Society, 17(2), 139-156. https://doi.org/10.1080/ 17430437.2013.790897

Hermens, N., Super, S., Verkooijen, K. T., \& Koelen, M. A. (2015). Intersectoral action to enhance the social inclusion of socially vulnerable youth through sport: An exploration of the elements of successful partnerships between youth work organisations and local sports clubs. Social Inclusion, 3(3), 98-107. http:// dx.doi.org/10.17645/si.v3i3.139

Hermens, N., Super, S., Verkooijen, K. T., \& Koelen, M. A. (2017). A systematic review of life skill development through sports programs serving socially vulnerable youth. Research Quarterly for Exercise and Sport, 88(4), 408-424. https://doi.org/10.1080/02701367. 2017.1355527

Hermens, N., Verkooijen, K. T., \& Koelen, M. A. (2019). Associations between partnership characteristics and perceived success in Dutch sport-for-health partnerships. Sport Management Review, 22(1), 142-152. https://doi.org/10.1016/j.smr.2018.06.008

Holt, N. L., Neely, K. C., Slater, L. G., Camiré, M., Côté, J., Fraser-Thomas, J., . . . Tamminen, K. A. (2017). A grounded theory of positive youth development through sport based on results from a qualitative meta-study. International Review of Sport and Exercise Psychology, 10(1), 1-49. https://doi.org/ 10.1080/1750984X.2016.1180704

Hsieh, H. F., \& Shannon, S. E. (2005). Three approaches to qualitative content analysis. Qualitative Health Research, 15(9), 1277-1288. https://doi.org/10.1177/ 1049732305276687

Jones, G. J., Edwards, M. B., Bocarro, J. N., Bunds, K. S., \& Smith, J. W. (2017). An integrative review of sportbased youth development literature. Sport in Society, 20(1), 161-179. https://doi.org/10.1080/17430437. 2015.1124569

Koelen, M. A., Vaandrager, L., \& Wagemakers, A. (2012). The healthy alliances (HALL) framework: Prerequisites for success. Family Practice, 29(1), 132-138. https://doi.org/10.1093/fampra/cmr088

Kozlowski, S. W. J., \& Bell, B. S. (2003). Work groups and teams in organizations. In W. C. Borman, D. R. Ilgen, \& R. J. Klimoski (Eds.), Handbook of psychology: Industrial and organizational psychology (Vol. 12, pp. 333-375). Hoboken, NJ: Wiley.

Levermore, R., \& Beacom, A. (2009). Sport and development: Mapping the field. In R. Levermore \& A. Beacom (Eds.), Sport and international development (pp. 1-25). London: Palgrave Macmillan.

Lewin, K. (1951). Field theory in social science. New York, NY: Harper \& Row.

Lindsey, I., \& Bitugu, B. B. (2019). Partnerships in and around SDP. In H. Collison, S. C. Darnell, R. Giulianotti, \& P. D. Howe (Eds.), Routledge handbook of sport for development and peace (pp. 152-161). New York, NY: Taylor \& Francis.
Marlier, M., Lucidarme, S., Cardon, G., de Boudeauduij, I., Babiak, K., \& Willem, A. (2015). Capacity building through cross-sector partnerships: A multiple case study of a sport program in disadvantaged communities in Belgium. BMC Public Health, 15. https://doi. org/10.1186/s12889-015-2605-5

Misener, K. E., \& Doherty, A. (2012). Connecting the community through sport club partnerships. International Journal of Sport Policy and Politics, 4(2), 243-255. https://doi.org/10.1080/19406940. 2012.674962

Nols, Z., Haudenhuyse, R., \& Theeboom, M. (2017). Urban sport-for-development initiatives and young people in socially vulnerable situations: Investigating the 'deficit model.' Social Inclusion, 5(2), 210-222. http:// dx.doi.org/10.17645/si.v5i2.881

Porro, N. (2020). Welfare and sports policies in contemporary Italy. In N. Porro, S. Martinelli, \& A. Testa (Eds.), Sport, welfare and social policy in the European Union (pp. 142-157). New York, NY: Routledge.

Regoliosi, L., \& Scaratti, G. (2010). La prevenzione del disagio giovanile [Prevention of juvenile social disease]. Roma: Carrocci Editori.

Sanchéz, R. M., Gozzoli, C., \& D’Angelo, C. (2013). Can sport include people? Risks and chances. Revista Iberoamericana de Psicologia del Ejercicio y el Deporte, 8(1), 164-182.

Scaratti, G., Gorli, M., \& Ripamonti, S. (2009). The power of professionally situated practice analysis in redesigning organisations: A psychosociological approach. Journal of Workplace Learning, 21(7), 538-554. https://doi.org/10.1108/ 13665620910985531

Schaillée, H., Haudenhuyse, R., \& Bradt, L. (2019). Community sport and social inclusion: International perspectives. Sport in Society, 22(6), 885-896. https:// doi.org/10.1080/17430437.2019.1565380

Schulenkorf, N. (2012). Sustainable community development through sport and events: A conceptual framework for sport-for-development projects. Sport Management Review, 15(1), 1-12. https://doi.org/ 10.1016/j.smr.2011.06.001

Smith, J. A., \& Osborn, M. (2008). Interpretative phenomenological analysis. In J. A. Smith (Ed.), Qualitative psychology: A practical guide to research methods (2nd ed., pp. 53-80). London: Sage.

Spaaij, R. (2012). Building social and cultural capital among young people in disadvantaged communities: Lessons from a Brazilian sport-based intervention program. Sport, Education and Society, 17(1), 77-95. https://doi.org/10.1080/13573322.2011.607913

Sperling, J. (2020). "I just want to finish high school like everybody else": Continuation high school students resist deficit discourse and stigmatization. Equity \& Excellence in Education, 52(5), 465-484. https://doi. org/10.1080/10665684.2019.1691960

Stelter, R. (2009). Coaching as a reflective space in a society of growing diversity-towards a narrative, post- 
modern paradigm. International Coaching Psychology Review, 4(2), 207-217.

Stelter, R. (2014). Third generation coaching: Reconstructing dialogues through collaborative practice and a focus on values. International Coaching Psychology Review, 9(1), 51-66.

Svensson, P. G., \& Woods, H. (2017). A systematic overview of sport for development and peace organisations. Journal of Sport for Development, 5(9), 36-48.

Vandermeerschen, H., Vos, S., \& Scheerder, J. (2015). Who's joining the club? Participation of socially vulnerable children and adolescents in club-organised sports. Sport, Education and Society, 20, 941-958. https://doi.org/10.1080/13573322.2013.856293

Whitley, M. A., Massey, W. V., Camiré, M., Blom, L. C., Chawansky, M., Forde, S., . . Darnell, S. C. (2019). A systematic review of sport for development interventions across six global cities. Sport Management Review, 22(2), 181-193. https://doi.org/10.1016/j.smr. 2018.06.013

Yohalem, N., Wilson-Ahlstrom, A., Fischer, S., \& Shinn, M. (2009). Measuring youth programme quality: A guide to assessment tools ( $2 \mathrm{nd}$ ed.). Washington, DC: The Forum for Youth Investment.

\section{About the Authors}

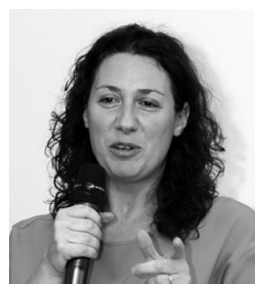

Chiara D'Angelo is Assistant Professor at the Faculty of Psychology of the Cattolica University where she teaches Work and Organizational Psychology and coordinates the Postgraduate Course of Specialization 'Sport and Psychosocial Intervention.' She did a PhD in Psychology on sport coaches identity. She has special interest in monitoring and evaluation of sport-based programs aimed at social inclusion of socially vulnerable population.

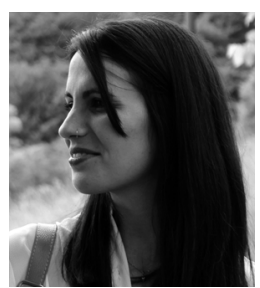

Chiara Corvino is a PhD Candidate in Psychology at the Catholic University of Milan. Her research focuses on sport as a tool for the inclusion of socially vulnerable youth in the Italian context.

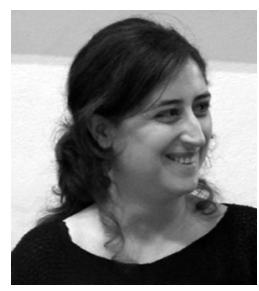

Eloisa Cianci has a PhD in Anthropology and Epistemology of the Complexity at the University of Bergamo. She is lecture in Clinical Psychology of Groups and Organizations at the Faculty of Psychology at the Catholic University of Milano. She currently works as a project planner and manger for several European projects related to sport and social issues.

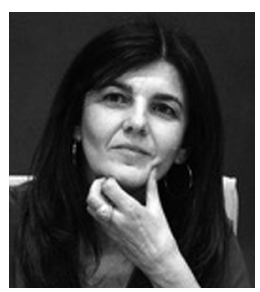

Caterina Gozzoli is Full Professor at the Faculty of Psychology of the Catholic University of Milan where she teaches Psychology of the Co-living and Clinical Psychology of Groups and Organizations. She has special interest in trans-cultural competences and evaluation of sport-based programs aimed at social inclusion of socially vulnerable population. 